\title{
Context Defined Aspects of Gamification for Factory Floor
}

\author{
Paula Alavesa \\ Center for Ubiquitous Computing \\ University of Oulu \\ Oulu, Finland \\ paula.alavesa@oulu.fi
}

\author{
Ilmo Laitalainen \\ $A B B$ Smart Power \\ $A B B$ Group \\ Vaasa, Finland \\ ilmo.laitalainen@fi.abb.com
}

\author{
Milla Immonen \\ Smart Health \\ VTT Technical Research Centre \\ Oulu, Finland \\ milla.immonen@vtt.fi
}

\begin{abstract}
Modern extensively digitized factories can provide workers interfaces for gamification. The current literature highlights the importance of understanding the context before implementing gamification solution, while there are currently only few such solutions provided for the factory floor. In this study we aim at closing this gap by defining the context defined aspects for gamification at factory floor. We conducted a thorough mapping of current literature proceeded by a qualitative interview study with eight workers and their supervising manager at a manufacturing facility.
\end{abstract}

\section{Keywords-gamification, serious games, factory floor}

\section{INTRODUCTION AND RELATED WORK}

Although as a concept gamification has been around for a while $[1,2]$. It is a new field in academic research, spanning over a decade of reported findings [3]. Companies have also just recently begun to understand the value of employee's job satisfaction on productivity $[4,5]$. There is recent evidence on the importance of intangible and human assets to companies and knowledge that job satisfaction of the employees has a positive impact in customer retention [5], productivity [6] and equity [4]. However, stock markets and investors do not fully value the intangibles [4]. Operation centric approach adopted in many companies aims at optimizing the production, which can result in neglecting the impact human resources to production [5]. Hämäri et al. [7] in their extensive review focused on motivational affordances incorporated into the gamified applications and found that only papers of the topic have an empirical approach. They noted that only four out of the 24 analyzed papers were in the context of "work" and an additional four were in "Intra-organizational systems". The gamification in those studies has however been issued to office workers or managers. The workers in papers reviewed by Hämäri et al. [7] were, program developers [8, 9] and people professionally or semi-professionally providing human intelligence task work $[10,11]$. What these workers have in common is a constant access to digital interfaces while working.

Gamification seems to especially benefit the experience in monotonous and respective tasks. Despite the positive results in many application fields, to our knowledge, direct and persistent implementation to the factory floor has not yet happened for any gamification solution. Processes that are familiar for factory floor workers such as calibration have been targeted, yet the solutions have been evaluated by people recruited from university community [12]. Kampker et al. [13] developed a model for gamifying learning phase while ramping up production on a new production line in an automotive factory. They implemented two games for learning an assembly sequence of the new product and ran evaluations on site. The current research on gamification admits that participants and context influence the effectiveness of gamification [7, 14]. Di Tomasso's [15] recommendations for successful gamification start from identifying individual participants' differences, the social influences in their context and motivational drivers. According to many similar approaches based on selfdetermination theory (SDT) [16] the purpose of gamification is to increase intrinsic motivation by providing extrinsic motivators. It has been since shown that some of these approaches such as points, levels, leaderboards [17] and other elements can increase task performance [6].

While paying attention to graphic design Korn [18] designed a gamified interface for a workstation screen. The purpose of the approach was to enrich elderly and impaired workers work environment. He however only describes the design of a standalone game design and no evaluation or prestudies on site, which is why the value of the approach is difficult to assess. Kampker et al. [13] describe an application for teaching assembly on a new production line at an automotive factory. This application was evaluated with mixed results on site, but despite Kampker et al. describing the approach gamification the application itself could be described as a standalone serious game. In addition, some tasks that are commonplace in many work environments, such as calibration [12], have been targeted for gamification. Gamification failures have been attributed to poor or missing design. This relates to not understanding the context and its related factors [19]. When the rewards are not tied to the real motivating factors and deep understanding of the context many gamification approaches end up having unintended affects [19].

\section{METHOD AND MATERIAL}

The study (Fig. 1) was initiated with a mapping study conducted during November-January 2018-2019 using Google Scholar search.

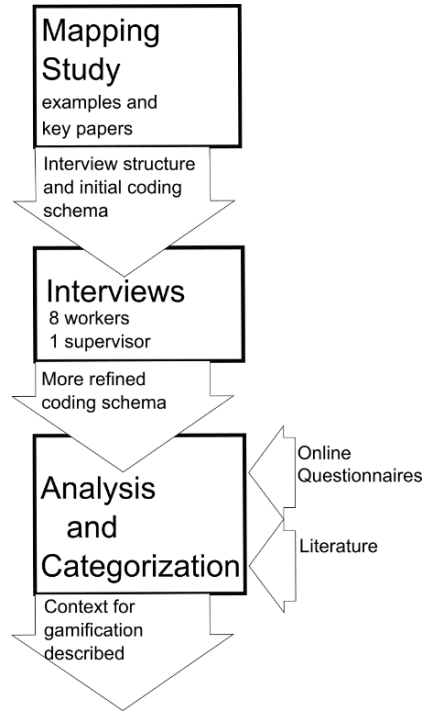

Fig. 1. The progress of this study. 
Papers in peer reviewed proceedings or journals published 2000-2019 were considered. In addition, only papers discussing gamification in industry context were reviewed. The used search phrases were: "Industry Gamification", "serious games factories" and "serious games industry" the search phrases produced many redundant hits, due to the ambiguity of the search phrases. The context, motivation and attitudes towards gamification were mapped with semistructured interviews of eight factory workers and their supervising manager. One out of eight interviewed factory workers and their manager were male. They were aged 21-63. Interviews were $12-21 \mathrm{~min}$ long and conducted in manufacturing facility of ABB Protection and Connection, manufacturer of electrical switches, in Vaasa, Finland. The sample of nine was chosen, because they represent one team in a multiteam organization and therefore the sample specificity is high, with small variances, that can be targeted for to study. The audio recordings were transcribed by the researcher before qualitative analysis, coding and categorization.

\section{RESULTS}

The qualitative analysis of the interview material followed general qualitative coding principles [20]. The identified context defined features are:

People: The factory workers present heterogenous demographics agewise. In addition, they cannot be branded as digital natives or born gamers, this is a step outside the traditional justification for gamification approaches.

Motivation: The motivational source is work. Work motivation is therefore what needs to be targeted for evaluating gamification approaches and understood when applying gamification to a factory. One aspect influencing work motivation is achieving collaborative flow. This feature relates also to the Social aspects at workplace.

Attitudes: The factory workers prioritize work while at work place. Their attitudes change when they leave the factory and the context changes.

Social aspects: The collaborative flow and high appreciation of social interactions between the workers were the main described sources of enjoyment at the work place.

\section{CONCLUSION}

As the operation centric approach in optimizing factories is finding its limits there has been a shift towards appreciation of the human resources. Gamification has potential to enhance engagement and work motivation, therefore it provides one solution for more satisfied workers and attractive workplaces. We identified context and human dependent features that influence gamification in factory floor. These features fall under the known main themes in the background on many gamification frameworks: people, motivation, attitudes and social aspects. The features themselves are: heterogenous demographics, work motivation, prioritizing work, collaborative flow, high collaboration (low competition). These specific features need to be taken into consideration and used to adapt the existing design guidelines suitable for factory floor context. In the future we are expanding our study to other collaborating factories with the aim of more generalizable results.

\section{ACKNOWLEDGMENTS}

This research is done in a Business Finland funded project Reboot Finland IoT Factory 33/31/2018 supported by Academy of Finland 6Genesis Flagship (318927).

\section{REFERENCES}

[1] A. V. Kamasheva, E. R. Valeev, R. K. Yagudin, and K. R. Maksimova, "Usage of gamification theory for increase motivation of employees," Mediterranean Journal of Social Sciences, vol. 6, no. 1 S3, p. 77, 2015.

[2] N. Pelling, "The (short) prehistory of 'gamification'...," Funding Startups (\& other impossibilities), 09-Aug-2011.

[3] S. Deterding, R. Khaled, L. E. Nacke, and D. Dixon, "Gamification: Toward a definition," in CHI 2011 gamification workshop proceedings, 2011, vol. 12.

[4] A. Edmans, "Does the stock market fully value intangibles? Employee satisfaction and equity prices," Journal of Financial Economics, vol. 101, no. 3, pp. 621-640, Sep 2011.

[5] R. W. Y. Yee, A. C. L. Yeung, and T. C. E. Cheng, "The impact of employee satisfaction on quality and profitability in high-contact service industries," Journal of Operations Management, vol. 26, no. 5, pp. 651-668, Sept 2008.

[6] E. D. Mekler, F. Brühlmann, K. Opwis, and A. N. Tuch, "Do points, levels and leaderboards harm intrinsic motivation?: an empirical analysis of common gamification elements," in Proceedings of the First International Conference on gameful design, research, and applications, 2013, pp. 66-73.

[7] J. Hämäri, J. Koivisto, and H. Sarsa, "Does gamification work?--a literature review of empirical studies on gamification," in $201447 \mathrm{th}$ Hawaii international conference on system sciences (HICSS), 2014, pp. 3025-3034.

[8] A. Anderson, D. Huttenlocher, J. Kleinberg, and J. Leskovec, "Steering user behavior with badges," in Proceedings of the 22nd international conference on World Wide Web, 2013, pp. 95-106.

[9] S. Grant and B. Betts, "Encouraging user behaviour with achievements: an empirical study," in Proceedings of the 10th Working Conference on Mining Software Repositories, 2013, pp. 65-68.

[10] C. Eickhoff, C. G. Harris, A. P. de Vries, and P. Srinivasan, "Quality through flow and immersion: gamifying crowdsourced relevance assessments," in Proceedings of the 35th international ACM SIGIR conference on Research and development in information retrieval, 2012, pp. 871-880.

[11] J. Kumar, "Gamification at work: Designing engaging business software," in International conference of design, user experience, and usability, 2013, pp. 528-537.

[12] D. R. Flatla, C. Gutwin, L. E. Nacke, S. Bateman, and R. L. Mandryk, "Calibration games: making calibration tasks enjoyable by adding motivating game elements," in Proceedings of the 24th annual ACM symposium on User interface software and technology, 2011, pp. 403412.

[13] A. Kampker, C. Deutskens, K. Deutschmann, A. Maue, and A. Haunreiter, "Increasing Ramp-up Performance By Implementing the Gamification Approach," Procedia CIRP, vol. 20, pp. 74-80, 2014.

[14] G. Barata, S. Gama, J. Jorge, and D. Gonçalves, "Studying student differentiation in gamified education: A long-term study," Computers in Human Behavior, vol. 71, pp. 550-585, 2017.

[15] Dustin DiTommaso, "Beyond Gamification: Architecting Engagement Through Game Design Thin...," 18:04:49 UTC.

[16] R. M. Ryan and E. L. Deci, "Self-determination theory and the facilitation of intrinsic motivation, social development, and wellbeing.," American psychologist, vol. 55, no. 1, p. 68, 2000.

[17] K. Werbach and D. Hunter, For the win: How game thinking can revolutionize your business. Wharton Digital Press, 2012.

[18] O. Korn, "Industrial playgrounds: how gamification helps to enrich work for elderly or impaired persons in production," in Proceedings of the 4th ACM SIGCHI symposium on Engineering interactive computing systems, 2012, pp. 313-316.

[19] D. Rojas, B. Kapralos, and A. Dubrowski, "The missing piece in the gamification puzzle," presented at the Proceedings of the First International Conference on Gameful Design, Research, and Applications, 2013, pp. 135-13

[20] K. Charmaz, "Handbook of Interview Research,” Eds. J. Gubrium \& J. Holstein, SAGE Publications, Inc., 2011 